\title{
Evaluation of first trimester maternal serum and ultrasound screening for Down's syndrome in Eastern and Northern Finland
}

\author{
Marko Niemimaa ${ }^{1}$, Mikko Suonpää ${ }^{3}$, Antti Perheentupa ${ }^{1}$, Maija Seppälä ${ }^{3}$, Seppo Heinonen ${ }^{2}$, \\ Päivi Laitinen ${ }^{4}$, Aimo Ruokonen ${ }^{4}$ and Markku Ryynänen*,1
}

${ }^{1}$ Department of Obstetrics and Gynaecology, Oulu University Hospital, Oulo, Finland; ${ }^{2}$ Department of Obstetrics and Gynaecology, Kuopio University Hospital, Kuopio, Finland; ${ }^{3}$ Wallac OY, Turku, Finland; ${ }^{4}$ Department of Clinical Chemistry, Oulu University Hospital, Oulo, Finland

The current trend in prenatal diagnosis is that trisomy screening is being moved to the first trimester and ultrasonographic nuchal translucency measurement is included in risk calculation. It is likely that biochemical screening in the second trimester will gradually be given up. In Eastern and Northern Finland, during the year 1999 we offered first-trimester ultrasonographic and serum screening for trisomy 21, with measurements of maternal serum PAPP-A and $\beta$-hCG. A total of 2515 pregnant women participated in the screening, yielding the detection of eight foetuses with Down's syndrome. Six affected foetuses (75\%) were detected by means of first-trimester serum screening. Since we were in the phase of collecting data for the Finnish medians for PAPP-A and $\beta$-hCG, the women were not given the estimates of risk for trisomy 21. Only 1602 of the $\mathbf{2 5 1 5}$ enrolled women had the combination of first-trimester ultrasonographic and serum screening performed, and in that group there were five foetuses with Down's syndrome. The combination ultrasonographic and serum approach yielded a Down's syndrome detection rate of $\mathbf{8 0 \%}$ (four out of five) with a $5 \%$ false positive rate, whereas in nuchal translucency based-screening the detection rate was $60 \%$, with a 5\% false positive rate. European Journal of Human Genetics (2001) 9, 404-408.

Keywords: prenatal diagnosis; Down's syndrome; first trimester trisomy screening; maternal serum screening

\section{Introduction}

Prenatal diagnosis has become an increasingly important part of the management of pregnancies in Western countries. This is due to both the delay in childbearing following longer education among women, and to a growing awareness of the frequency and importance of congenital disorders. Furthermore, the current social trend is toward smaller families. Down's syndrome is still the primary reason for families to seek prenatal counselling. The current standard of care has

*Correspondence: M Ryynänen, Department of Obstetrics and Gynaecology, Oulu University Hospital, 90221 Oulu, Finland.

Tel: +358 8315 3171; Fax: +358 8315 4310;

E-mail:markku.ryynanen@oulu.fi

Received 21 September 2000; revised 18 March 2001; accepted 20 March 2001 been to offer women the maternal serum test in the 15th16 th weeks of pregnancy. However, there is a growing demand to have a screening test earlier, in the first trimester. Nicolaides ${ }^{1}$ in the UK and Ville ${ }^{2}$ in France introduced the first trimester ultrasound screening for trisomy in 1992. These early findings were later confirmed by larger studies, which demonstrated that foetal nuchal translucency is an efficient method of screening for Down's syndrome in the first trimester $^{3,4}$. In 1992, Wald et al. ${ }^{5}$ proposed the use of pregnancy associated plasma protein A (PAPP-A) and placental protein 14 in trisomy 21 screening. Published findings report that combining free $\beta$-hCG and PAPP-A with maternal age and crown-rump length by using mathematical models allows the detection of trisomy 21 at a rate of $53-$ $68 \%$ with a $5 \%$ screen-positive rate ${ }^{6-8}$. Scott et al. ${ }^{9}$ assessed nuchal translucency, free $\beta$-hCG and maternal age; multi- 
variant discriminant analysis enabled an $87.5 \%$ detection rate in high-risk population with a $14 \%$ false positive rate. The efficacy of biochemical screening increases if the measurement of nuchal translucency thickness is included in calculating the risk figure. The sensitivity of Down's syndrome detection is thus increased to $85-89 \%$ at a fixed false positive rate of $5 \% .{ }^{10-19}$ The results of the published screening tests are shown in Table 1.

In our study we have studied the efficacy of combining the first trimester maternal serum test and foetal nuchal translucency measurement in screening for Down's syndrome in Finland.

\section{Subjects and methods}

Since the granting of the maternity allowance provided by the Finnish state is dependent on the completion of a registration procedure, most pregnant women sign themselves into antenatal clinics at health centres, usually between their 6 th and 13th weeks of pregnancy. Health care providers, mostly midwives, gave information on the research project to all pregnant women in Eastern and Northern Finland during their first visit, emphasising that the participation in the screening was completely voluntary. All subjects gave informed written consent before being enrolled in the study. The Research-Ethics Committee of the participating hospitals approved the study.

The screening test, PAPP-A and $\beta$-hCG and ultrasound were offered free of charge. Blood samples were drawn in primary care centres and in maternity clinics of the participating university and central hospitals. Gestational ages ranged from 10 weeks 0 days to 13 weeks 6 days and were based on ultrasound (most cases, 82\%) or last menstrual period if ultrasound was not done. Blood samples were sent to Wallac OY, Turku, Finland where the maternal serum PAPP-A and $\beta$-hCG concentrations were analysed. The within and between assay variation for $\beta$-hCG were both $<3.4 \%$ and for PAPP-A $<1.4 \%$ and

Table 1 Estimated detection rate for trisomy 21 by a combination of maternal age, foetal nuchal translucency and first-trimester maternal serum PAPP-A and free $\beta$-hCG at a $1-14 \%$ screen-positive rate

\begin{tabular}{|c|c|c|c|c|}
\hline Study & Trisomy 21 & $\begin{array}{l}\text { Gestation } \\
\text { (weeks) }\end{array}$ & $\begin{array}{l}\text { Screen- } \\
\text { positive (\%) }\end{array}$ & $\begin{array}{l}\text { Detection } \\
(\%)\end{array}$ \\
\hline Brizot et $a l^{10}$ & 80 & $10-14$ & 5.0 & 89 \\
\hline Scott et al. ${ }^{9}$ & & $10-13$ & 14.0 & 87.5 \\
\hline Zimmerman et al..$^{11}$ & 4 & $10-13$ & $2^{*}$ & $39 *$ \\
\hline Wald et al..$^{13}$ & $86+77$ & $10-14$ & 5.0 & 80 \\
\hline Orlandi et al. ${ }^{12}$ & 11 & $9-14$ & 5.0 & 87 \\
\hline de Graaf et al. ${ }^{16}$ & 37 & $10-14$ & 5.0 & 85 \\
\hline de Biasio et al. ${ }^{15}$ & 13 & $10-14$ & 3.3 & 85 \\
\hline Spencer et al. ${ }^{17}$ & 210 & $10-14$ & 5.0 & 89 \\
\hline Krantz et al. ${ }^{18}$ & 50 & $10-14$ & 4.5 & 87.5 \\
\hline Spencer et al. ${ }^{19}$ & 7 & $10-14$ & 6.7 & 86 \\
\hline
\end{tabular}

*For an increased nuchal translucency and decreased PAPP-A.
$<4.8 \%$, respectively. The analytical sensitivities of $\beta$-hCG and PAPP-A were $0.2 \mathrm{ng} / \mathrm{ml}$ and $5 \mathrm{mU} / \mathrm{l}$, respectively. The results are given as multiples of medians (MoM). Quality was assessed regularly, using in-house controls. The risk figures for biochemical tests, nuchal translucency and for combined test were calculated using the software program of Wallac $1 \mathrm{~T}$ risk calculation program (research version), ${ }^{20}$ which is based on the principles previously introduced. Wallac's program has been extended to include pregnancies before the 11th week of pregnancy.

The assay laboratory was provided with the following patient information: date of birth, weight, first day of last menstrual period, gestational age by ultrasound and the nuchal translucency thickness (if available), diabetic status, use of insulin, and the number of foetuses. Nuchal translucency was estimated in university or central hospitals or in health-care centres by personnel trained in tertiary university centres. The results of the serum test were not given to the patients.

In the ultrasound screening we used a cut-off limit of $\geqslant 3 \mathrm{~mm}$ for the nuchal translucency thickness, and the risk figure was also calculated by the Wallac program. The risk figure program takes into account the maternal age, crownrump length and foetal nuchal translucency thickness. The estimate of risk for Down's syndrome for a specific maternal age remained investigational. If the nuchal translucency thickness was $\geqslant 3 \mathrm{~mm}$, foetal chromosome investigation was offered.

In the biochemical screening we used the risk-calculation program of Wallac. Women with a risk greater than that of a 35 -year-old at the same gestational age, ie $1: 250$, were considered to be at increased risk for Down's syndrome. We also calculated the cut-off limit for a fixed false positive rate of $5 \%$.

In the combined biochemical and nuchal translucency screening we used the Wallac program for calculating the risk figure. Corrections were made for maternal weight but not for diabetic status or smoking. The cut-off limit for increased risk was set at $1: 250$.

In order to identify Down's syndrome infants born to screen-negative women enrolled in the study, we contacted all maternity clinics and the Finnish Register of Congenital Malformation, and the National Research and Development Centre for Welfare and Health, to get information on newborns with Down's syndrome.

\section{Results}

The participants comprised 2515 volunteer pregnant women in Eastern and Northern Finland during the 10th-13th weeks of pregnancy in 1999. First the Finnish medians for maternal serum concentration of PAPP-A and $\beta$-hCG were calculated. The expected number of Down's syndrome in our study group according to the Finnish Register of Congenital Malformation was $7.8(1: 324)$. Among the screenees there 
were eight cases of trisomy $21(1: 314)$ and two cases of trisomy 18 (1:1257). Of the pregnant women, $17.5 \%$ were older than 35 years, a figure that conforms exactly to the average Finnish pregnancy statistics. ${ }^{21}$ Nuchal translucency of the foetus was measured in 1602 of the pregnancies. Five cases of trisomy 21 and both cases of trisomy 18 were found in that group.

\section{The biochemical test only}

In the population screened by the biochemical test only, a total of 249 women $(9.9 \%=$ initially positive $)$ had the adjusted estimated risk of at least 1 in 250. Six foetuses of the eight (75\%) affected by Down's syndrome (Tables 2 and 3) and the foetuses with trisomy 18 were detected on the basis of serum screening. At a fixed 5\% false positive rate, the cutoff limit was 1:140 and the detection rate remained the same, $75 \%$. In the age group of 16-20 years the false positive rate was $14 \%(n=63)$, and in the age group of women $\geqslant 35$ years the false positive rate was $18 \%(n=460)$.

\section{Nuchal translucency only}

In the population screened by nuchal translucency only, a total of 189 women $(7.5 \%=$ initially positive $)$ had the adjusted estimated risk of at least 1 in 250 for Down's syndrome calculated by the risk figure program. Among the 1602 screenees there were five pregnancies affected by Down's syndrome (the frequency of Down's was 1:320), and two by trisomy 18. Three foetuses affected by Down's syndrome, 60\% (Tables 2 and 3), and the foetuses with trisomy 18 were detected by nuchal translucency screening.

\section{Biochemical and nuchal translucency combined}

In the screened population, a total of 136 women $(5.4 \%=$ initially positive) constituted the risk group for Down's syndrome. Among the screenees there were five pregnancies affected by Down's syndrome, and two by trisomy 18. Four foetuses affected by Down's syndrome, 80\% (Tables 2 and 3), and the foetuses with trisomy 18 were detected on the basis of the combined screening.

\section{Discussion}

It is generally believed that screening for trisomies using maternal age alone has a low detection rate and a high false positive rate. ${ }^{10}$ This may be true for countries where the proportion of older women ( $>35$ years of age) is $10 \%$ or less. But in Finland, where $17.5 \%$ of pregnant women are 35 years of age or older, the 'age screening' would detect more than half of all cases of Down's syndrome. In the whole country of Finland, 58\% of cases of trisomy 21 in 1999 were in the group of older women and 39\% of all detected Down's syndromes were found in that group (the uptake of prenatal diagnostics is not 100\%). The proportion of older women in the screened population has an
Table 2 Results of screening for trisomy 21 by assay of maternal serum (PAPP-A and $\beta$-hCG), by foetal nuchal translucency and by combining maternal serum biochemistry and foetal nuchal translucency at 10-13 weeks of gestation using 1:250 as a cut-off limit. There were eight cases of Down's syndrome in the maternal serum group and five cases in the other groups

\begin{tabular}{lllll}
\hline & & $\begin{array}{l}\text { Screen } \\
\text { positives } \\
\mathrm{n}(\%)\end{array}$ & $\begin{array}{l}\text { No of } \\
\text { Down's } \\
\text { detected }\end{array}$ & $f$ \\
\hline Maternal serum & 2515 & $249(9.9)$ & $6 / 8$ & $1: 35$ \\
Nuchal translucency & 1602 & $189(7.5)$ & $3 / 5$ & $1: 63$ \\
Combined & 1602 & $136(5.4)$ & $4 / 5$ & $1: 34$ \\
\hline
\end{tabular}

$\mathrm{f}=$ frequency of Down's in screen positive cases.

Table 3 Cases of trisomy 21 identified in the screened population during the period January 1, 1999 to December 31, 1999. NT=foetal nuchal translucency thickness

\begin{tabular}{lcccccc}
\hline Case & Age & Gestation & $\begin{array}{c}N T \\
\mathrm{~mm}\end{array}$ & $\begin{array}{c}N T \\
\text { only risk }\end{array}$ & $\begin{array}{c}\text { Biochem } \\
\text { risk }\end{array}$ & $\begin{array}{c}\text { Combined } \\
\text { risk }\end{array}$ \\
\hline 1 & 27 & $12+4$ & 1.7 & $1: 1584$ & $1: 35$ & $1: 64$ \\
2 & 30 & $12+5$ & 0.6 & $1: 2111$ & $1: 1875$ & $1: 2142$ \\
3 & 21 & $10+3$ & - & - & $1: 37$ & - \\
4 & 35 & $12+6$ & - & - & $1: 37$ & - \\
5 & 31 & $13+0$ & 5.0 & $1: 10$ & $1: 294$ & $1: 10$ \\
6 & 38 & $12+4$ & 3.7 & $1: 10$ & $1: 83$ & $1: 10$ \\
7 & 44 & $13+0$ & 6.2 & $1: 10$ & $1: 10$ & $1: 10$ \\
8 & 43 & $11+5$ & - & - & $1: 30$ & - \\
\hline
\end{tabular}

influence on the prevalence of Down's syndrome. The number of Down's cases will increase with the increasing proportion of older women, $\geqslant 35$ years.

The proportion of older women also has an influence on the false positive rate, since the risk programs emphasise the maternal age: the greater the proportion of older women, the higher the false positive rate. On the other hand, the greater the proportion of older women, the better the detection rate. The rising false positive rate is an important issue in populations with a high proportion of older women since it increases the number of invasive procedures. Therefore, in the future, it would be important to find a risk program independent of maternal age.

At a fixed $5 \%$ false positive rate Krantz et al. ${ }^{18}$ reported a $91 \%$ detection rate and a cut-off figure of $1: 270$. Spencer $e t$ al. ${ }^{19}$ reported an $86 \%$ detection rate and a cut-off figure of $1: 300$. In our study, a fixed $5 \%$ false positive rate, the cutoff figure was 1:200 with an 80\% detection rate. The differences in cut-off figures may reflect the difference in the proportion of older women: in Krantz's study $34.6 \%$ of the women were $\geqslant 35$ years old and the frequency of Down's was $1: 173$, in Spencer's study $12.7 \%$ of the screenees were aged $\geqslant 35$ years, and the frequency of Down's was $1: 537$. In the study by Zimmerman et al. ${ }^{11}$ the 
frequency of Down's was 1:287, but $63 \%$ of the screenees were in the group of older women ( $\geqslant 35$ years). The expected and detected numbers of Down's syndrome in our study match closely.

A potential bias in our study could result from the loss of foetuses with Down's syndrome. We have not studied the foetal chromosomes in pregnancy losses. Studies by Snijders et al. $^{22}$ and Morris et al. $^{23}$ found that the foetal loss rate between late first trimester and term was $c a$. 31\%. This means that the detection rate of the screening test is overestimated, since undetected cases of Down's syndrome were aborted before term. A significant proportion of foetal losses occur between first and second trimester; therefore in order for a first trimester test to be considered superior to one performed in the second trimester, the detection rate should be at least $8.3 \%$ higher. $^{24}$

Using first trimester biochemical or ultrasound screening alone it is possible to detect $63 \%$ and $74 \%$ respectively of trisomy 21 cases at a fixed 5\% screen-positive rate. ${ }^{1,2,5,6}$ Each screening method has a Down's syndrome detection rate similar or better than mid trimester double or triple serum screening. Furthermore, the first trimester screening offers the advantage of having the screening results earlier, allowing more time for counselling and consideration of the result.

Modern trisomy screening combines first trimester serum biochemical test with the thickness of foetal nuchal translucency. Years of practical experience in this line of screening have already been gained, as shown in Table 1 . Our findings are in keeping with the studies of combined screening published earlier. ${ }^{10-14}$ The studies referred to show clearly that biochemical screening is more efficient if the nuchal translucency is included in calculating the risk figure: the efficacy increases by $15 \%$. This is true the other way round too: the efficacy of nuchal translucency screening can be improved by adding biochemical data to the risk figure software program. In our study the additional effect of ultrasound was not so obvious, possibly due to the rather limited number of trisomy cases. Despite limited numbers of Down's cases in nuchal translucency screening, we endorse the view that the application of the risk figure program is superior to the use of a simple cut-off limit of $\geqslant 3 \mathrm{~mm}$ in estimation of the risk for Down's syndrome in nuchal translucency screening.

We also draw attention to the important issue of the audit and quality assurance in the ultrasound screening context. Since January 2000 in one tertiary University centre (Oulu), ultrasound audit has been carried out by an independent agency (Fetal Medicine Foundation).

This study suggests that by combining the biochemical and ultrasound screening tests, we have a test which can be performed already in the first trimester and which promises a better sensitivity than the current testing procedures used in Down's syndrome screening.

\section{References}

1 Nicolaides KH, Snijders RJ, Gosden CM, Berry C, Campbell S: Ultrasonographically detectable markers of fetal chromosomal abnormalities. Lancet 1992; 340: $704-707$.

2 Ville Y, Lalondrelle C, Doumerc S et al: First trimester diagnosis of nuchal anomalies: Significance and fetal outcome. Ultrasound Obstet Gynecol 1992; 2: 314-316.

3 Snijders R, Noble P, Sebire N, Souka A, Nicolaides K: UK multicentre project on assessment of risk of trisomy 21 by maternal age and fetal nuchal translucency thickness at 10-14 weeks of gestation. Lancet 1998; 351: 343-346.

4 Taipale P, Hiilesmaa V, Salonen R, Ylöstalo P: Increased nuchal translucency as a marker for fetal chromosomal defects. $N$ Engl J Med 1997; 337: $1654-1658$.

5 Wald N, Stone R, Cuckle HS et al: First trimester concentrations of pregnancy associated plasma protein $\mathrm{A}$ and placental protein 14 in Down's syndrome. BMJ 1992; 305: 28.

6 Spencer K, Aitken D, Crossley J et al: First trimester biochemical screening for trisomy 21: the role of free beta-hCG, alpha fetoprotein and pregnancy associated plasma protein A. Ann Clin Biochem 1994; 31: 447-454.

7 Krantz D, Larsen J, Buchanon D, Macri J: First-trimester Down syndrome screening: free beta-human chorionic gonadotropin and pregnancy-associated plasma protein A. Am J Obstet Gynecol 1996; 174: 612-616.

8 Haddow JE, Palomaki GE, Knight GJ, Williams J, Miller WA, Johnson A: Screening of maternal serum for fetal Down's syndrome in the first trimester. N Engl J Med 1998; 338: 955 - 961.

9 Scott F, Wheeler D, Sinosich M, Boogert A, Anderson J, Edelman D: First trimester aneuploidy screening using nuchal translucency, free beta human chorionic gonadotrophin and maternal age [see comments]. Australian NZ J Obstet Gynaecol 1996; 36: $381-384$.

10 Brizot ML, Snijders R, Butler J, Bersinger N, Nicolaides KH: Maternal serum hCG and fetal nuchal translucency thickness for the prediction of fetal trisomies in the first trimester of pregnancy. Br J Obstet Gynaecol 1995; 102: $127-132$.

11 Zimmermann R, Hucha A, Savoldelli G, Binkert F, Achermann J, Grudzinskas JG: Serum parameters and nuchal translucency in first trimester screening for fetal chromosomal abnormalities. $\mathrm{Br}$ J Obstet Gynaecol 1996; 103: 1009 - 1014.

12 Orlandi F, Damiani G, Hallahan T, Krantz D, Macri J: Firsttrimester screening for fetal aneuploidy: biochemistry and nuchal translucency. Ultrasound Obstet Gynecol 1997; 10: 381 386.

13 Wald NJ, Hackshaw AK: Combining ultrasound and biochemistry in first-trimester screening for Down's syndrome [see comments]. Prenat Diagn 1997; 17: 821 - 829.

14 Biagiotti R, Brizzi L, Periti E, d'Agata A, Vanzi E, Cariati E: First trimester screening for Down's syndrome using maternal serum PAPP-A and free beta-hCG in combination with fetal nuchal translucency thickness. Br J Obstet Gynecol 1998; 105: 917-920.

15 DeBiasio P, Siccardi M, Volpe G, Famularo L, Santi F, Canini S: First-trimester screening for Down syndrome using nuchal translucency measurement with free beta-hCG and PAPP-A between 10 and 13 weeks of pregnancy-the combined test. Prenat Diagn 1999; 19: 130-133.

16 de Graaf I, Pajkrt E, Bilardo C, Leschot N, Cuckle H, van Lith J: Early pregnancy screening for fetal aneuploidy with serum markers and nuchal translucency. Prenat Diagn 1999; 19: 458 462.

17 Spencer K, Souter V, Tul N, Snijders R, Nicolaides K: A screening program for trisomy 21 at $10-14$ weeks using fetal nuchal translucency, maternal serum free beta-human chorionic gonadotropin and pregnancy associated plasma protein-A. Ultrasound Obstet Gynecol 1999; 13: 231-237.

18 Krantz DA, Hallahan TW, Orlandi F, Buchanan P, Larsen Jr, JW., Macri JN: First-trimester Down syndrome screening using dried blood biochemistry and nuchal translucency. Obstet Gynecol 2000; 96: 207-213. 
19 Spencer K, Spencer CE, Power M, Moakes A, Nicolaides K: One stop clinic for assessment of risk for fetal anomalies: a report of the first year of prospective screening for chromosomal anomalies in the first trimester. Br J Obstet Gynaecol 2000; 107: $1271-1275$

20 Soderback P, Seppala M, Suonpaa M: The autodelfia ${ }^{\circledR}$ assay for pregnancy associated plasma protein A (PAPP-A) to be used in the screening for Down syndrome in the first trimester of pregnancy. 10th International Conference, O59, Prenatal Diagnosis and Therapy, Barcelona, Spain, June 19-21, 2000.
21 Vital Statistics, in Population No. 13, Statistics Finland, Yliopistopaino, Helsinki, 2000.

22 Snijders, RJ, Sundberg K, Holzgreve W, Henry G, Nicolaides KH: Maternal age- and gestation-specific risk for trisomy 21. Ultrasound Obstet Gynecol 1999; 13: 167-170.

23 Morris JK, Wald NJ, Watt HC: Fetal loss in Down syndrome pregnancies. Prenat Diagn 1999; 19: 142-145.

24 Dunstan FD, Nix AB: Screening for Down's syndrome: the effect of test date on the detection rate. Ann Clin Biochem 1998; 35 $57-61$. 